\title{
Learning with and from Facebook: Uncovering power asymmetries in educational interactions
}

\author{
Patient Rambe \\ Central University of Technology, South Africa \\ Dick Ng'ambi \\ University of Cape Town, South Africa
}

\begin{abstract}
Although social networking sites (SNS) are increasingly popular among students, their academic application is unfolding on trial basis and best practices for integration into mainstream teaching are yet to be fully realised. More importantly, is the need to understand how these sites shape academic relations and participation of heterogeneous students, particularly in resource-constrained African environments. The speculation about meaningful educational uses of SNS possibly rests on the complexity of grasping the multiple horizontal and vertical interactions that unfold via these sites. This study examines academic relations on Facebook with a view to generating a nuanced account of how power is reinforced or disrupted in interactions mediated by Facebook. The paper analyses the Facebook wall and forum postings of 165 first year Information Systems students and employs Anderson's model of six types of interactions to explore student experiences of the enactments of social power in Facebook engagements. Issues relating to power that emerged from Facebook interactions concerned asymmetrical engagements based on gender, breaching of hierarchical boundaries, compulsive academic use of Facebook, perceptions of vertical surveillance, lecturer and student projection of themselves and impression management. The paper recommends that learning with and from Facebook demands identification of leverage points in various stages of Facebook interaction.
\end{abstract}

\section{Introduction}

Social networking sites (SNS) such as Facebook and Twitter are among the most trafficked sites on the Internet. For instance, Facebook boasts of 100 billion user connections worldwide, 30 million page views daily and over 37 million users from the African continent alone (InfographicLabs.com, 2012).Besides their surging popularity worldwide, another striking characteristic of SNS is their appropriation by young adults, which presents opportunities for heightened public performance of literacy and collaborative sharing of knowledge generated by peers. As of 16 January, 2013, 27\% of the 1 billion users registered on Facebook were young adults aged between 18-34 years (Envision Media, 2013). Since most university students comprise this age group, their academic and social engagements on Facebook would naturally be anticipated.

Despite the aforementioned phenomenal statistics and academia resonance of SNS, little is known about the implications of this increased presence for academic relations. Cummins (1997, p. 423) defines academic relations as "coercive and collaborative relations of power that operate at both the broader societal level (macrointeractions) and the interpersonal level (microinteractions)." Since social networked interaction is largely interpersonal in nature, understanding the architecture of educator-student and peer relations at micro levels might illuminate understanding of whether Facebook interactions reinforce, reproduce, subvert or transform micro relations of power. The challenge however, is that there is insufficient literature on how SNS reproduce or disrupt academic relations at micro level, that is, the power configurations between different lecturers and students in university contexts (Veletsianos \& Kimmons, 2012).

A handful of studies that attempted to unravel power relations in academia have concentrated on the equality of participation (Hoy \& Milne, 2010; Vedantham, 2011), alienation and disengagement (Selwyn \& Grant, 2009), impression management and self presentation (Maranto \& Barton, 2010; Dixon, 212; Velestianos, 2012), psychological tensions related to breaching social boundaries (Rambe \& Ng'ambi, 2011; Veletsianos \& Kimmons, 2012), and academic surveillance (Rambe, 2012). While these studies individually unravel a particular aspect of power, they do not provide a unified, synthesised account of how these multiple variables intersect and manifest themselves among previously disadvantaged students. 
With regard to asymmetrical participation on SNS, a study conducted by Vedantham (2011) on female and male university student participation in online video creation via Facebook and YouTube reports sharp gender asymmetries. Male students participated more in video creation and editing on SNS than female students. The study attributes this difference in participation to female students' attitudes towards, and confidence in, using computers. The study however, does not directly link participation on SNS to power relations enacted between academic interactants. With reference to identity management, SNS are harnessed to generate, project, sustain or even subvert particular professional identities. Veletsianos (2012) articulates how educators employ Twitter to foreground their professional identities and showcase their personal academic accomplishments, lectures and presentations they gave, as well as institutional successes recorded. This projection of strong academic authority (or a powerful academic identity) differs qualitatively from other presentations of the self documented in literature. In contrast to this, Rambe (2011) highlights the public performance of masculine identities by male students at a South African university through boasting about their posh places of residence on the Facebook group forum. Nevertheless, the aforementioned studies do not examine the complexity of micro relations between lecturer and students, as well as students and content.

In addition to identity management, other studies have targeted the nexus between self presentation, impression management and privacy. For instance, Maranto and Barton (2010) acknowledge that notwithstanding the potential of Facebook and MySpace to advance educator and student identity construction and presentation, students may fail to appreciate that their profiles might have a lasting negative impact. This is notwithstanding the view that surveillance potentially violates the individual privacy of students. Dixon (2012) documents how Facebook could be harnessed by students for presentation of the self through detailed narratives about their personal identities and for impression management through peers' critical questioning of their preferences. However, the aforementioned literature does not explore the intricate interplay of knowledge acquisition and the exercise of power in interactions mediated by Facebook. Yet the intersection of power and knowledge construction is aptly captured in Cummins's (1997) definition of micro [academic] interactions as an interpersonal space within which knowledge is acquired ... and power is shared.

Mindful of the foregoing discussion that does not sufficiently unravel micro level relations of power mediated by SNS, the configuration of horizontal (i.e., student-content, student-student) and vertical (i.e., lecturer-student) relations at university are explored to provide a nuanced account of how social media shapes, reproduces and transforms academic relations. This understanding is critical because despite the success of Facebook, claims about academic exclusion and inequalities at South African universities persist due to increased class sizes and diminishing educational resources (Bozalek \& Boughey, 2012). The paper reports on a case study that explored how first year Information Systems students at a South African university employed Facebook to mediate their academic relations to enhance their learning experiences. Some of the students were from previously disadvantaged socio-economic backgrounds.

\section{Methodology}

This study explores the following research questions:

1. How do interactions that are mediated by Facebook reinforce or disrupt academic relations (student-content, student-student and lecturer-student) in a traditional teaching environment?

2. What are the implications of these academic relations for pedagogy in resource-constrained environments?

\section{Conceptual framework}

Since the study sought to investigate how interactions mediated by Facebook reinforce or even disrupt micro level academic relations in a traditional teaching environment, it was deemed necessary to draw on social constructivist theories, which emphasise micro level interactions. Modern constructivist theorists stress the value of peer interaction in investigating and developing multiple perspectives (Anderson, 2004). Anderson's (2004) six types of interaction highlight three common modes of interaction (studentstudent; student-lecturer; student-content), and other types of interaction (lecturer-lecturer; lecturercontent; content-content). Given that Facebook interactions unfold at both horizontal levels (peer-based, 
student- content) and vertical levels (student-lecturer), Anderson's framework was ideal for exploring the power relations enacted in these interactions.

Anderson (2004) suggests that lecturer-content interaction pertains to the creation of content and design of learning activities by lecturers, and lecturer-lecturer interaction creates professional development and supports opportunities that sustain lecturers through communities of likeminded colleagues. Student-peer interactions denote the mutually beneficial exchange of academic information, sharing of knowledge and perspectives as well as socialisation among peers. Facebook also supports student-content interaction through students' individual selection of academic materials to complement resources provided in lectures and tutorials. These practices contribute to shifts in teaching methods that foster deep learning among students.

\section{Research design}

The preoccupation of the study with exploring whether the interactions mediated by Facebook reinforce or disrupt academic relations (student-content, student-student and lecturer-student) in a traditional teaching context meant that a methodological approach that emphasised the context and process of interaction was ideal. To this end, a case study approach, which emphasises the researcher's immersion in the life experiences of participants to obtain an intimate familiarity with their life worlds (Fouchè \& Schurink, 2011) was best suited for capturing the diverse micro academic relations that unfolded on Facebook. A case of first year undergraduate module offered in the Commerce Faculty at an elite South African university was considered in this study. A first year course was conceived as appropriate for this investigation because first year students often struggle to adjust to university life and to deal appropriately with the power relations that accompany this transition. This course was an introductory module comprising courses on Microsoft Access, Excel, and Introduction to Information Systems (IS). While Introduction to IS was a theoretical course, Microsoft Access and Excel were practical courses that involved the lecturer's use of instructional technology to demonstrate concepts in class followed by student assignments and quizzes in computer labs based on technical concepts learnt in lectures. The module was taught by two regular and three guest lecturers. The course convener taught Introduction to IS and convened the module, the regular lecturer taught Access and Excel, while guest lecturers occasionally delivered specific topics on the technical courses.

The 850 students who enrolled for the module comprised two mainstream classes with 400 previously advantaged students each and another class of 50 previously disadvantaged students (PDS), that is, the Academic Development Programme(ADP) class. The PDS are academically gifted students who came from under-resourced, underperforming high schools and display limited information and communication technology (ICT) literacy and poor study practices. The diverse academic backgrounds of these students and the associated implications for psychological empowerment meant that these classes were an ideal fit for unravelling micro level academic relations.

The IS department discerned the following challenges that necessitated the use of Facebook: (1) dealing with large classes during official consultations or after lectures, (2) prevalence of muted voices in large classes, especially the ADP students, (3) dominance of classroom interactions by few students, and (4) difficulty of assessing formatively the understanding and critical problem areas of students in the course. Therefore, in addition to the module's requirements for the use of an LMS, the IS department convenor created a Facebook group forum as a platform for students to communicate with peers and the regular lecturer via the Facebook wall, forum discussions and private messages. At the beginning of the course, all 850 students were instructed to create Facebook accounts and join the Facebook course group. This directive influenced the participation of different students depending on their academic motivation. The course administrator allocated an additional $2 \%$ to the term mark of all students who accomplished these tasks. 


\section{Ethical considerations and recruitment}

The lead researcher sought ethical clearance from the IS department head who approved the research. Subsequently, the course convenor introduced this researcher to all the students in lectures and explained his research intentions. He also solicited all students' cooperation with regard to this researcher's admission to the IS Facebook discussion forum. Subsequently, the researcher created his Facebook page and the convenor invited him to join the Facebook forum, thereby authorising his social presence and access to students' profiles. To build some rapport and mutual confidence with students as well as understand the context in which students' questions on Facebook emerged, the researcher attended all lectures and intermingled with students. Although, this study does not report on observations conducted in class, these interactions were instrumental in authenticating the researcher's online presence and his recognition by students as an insider. In-class observations allowed the researcher to understand the context in which Facebook queries were generated as well as ascertain the sincerity of postings.

\section{Data collection}

Given that participation in the Facebook group forum was limited to classmates, educators and the researcher, it was relatively easy to sample participants. The purposive sample drawn from Facebook comprised ADP and mainstream students who had consulted with their lecturer/peers on Facebook at least once. In total, 85 Facebook users were selected and contacted via the Facebook message feature for scheduled in-depth interviews. Of the 50 students who responded and were interviewed, 39 were mainstream students while 11 were from the ADP class. The individual interviews focused on student motivations for using Facebook, various interactions they had with peers, educators and content and how Facebook shaped their academic relations. The interviews with those students not using Facebook focused on their reasons for non-use of Facebook and their potential concerns with it. All interviews were conducted in a computer lab foyer, a conceivably safe and convenient space for most students. On average, an interview with a Facebook user lasted for about 45 minutes, while that with a non-user lasted about 30 minutes.

Five lecturers (course convenor, regular lecturer/Facebook administrator, and three guest lecturers) were also interviewed. Lecturers' interviews focused on their motivations for academic use of Facebook, the diverse interactions they had with students and colleagues and their implications for social power and their pedagogical strategies. Each interview lasted approximately 1 hour and was audio recorded, transcribed verbatim and analysed using thematic content analysis.

At the end of the second semester, the lecturer authorised the researcher to download her Facebook forum, wall postings and private consultations with students for in-depth analysis. These postings were mined to understand the nature and direction of postings, their gender balance and their implications for academic relations.

\section{Data analysis}

Thematic content analysis was used to compare topics emerging from the interviews and Facebook data with the categories already identified using the three interaction types from Anderson's model that could be detected in this data. In thematic content analysis, researchers identify topics or themes by means of line-by-line analysis, continually name categories by comparing new data incidents with categories already identified (Schurink, Fouchè \& De Vos, 2011).

\section{Interviews}

In this study, some themes were drawn from the topics articulated in interviews by participants. These pieces of data (i.e., interview data) were taken, coded, compared with other pieces of data (i.e., a category or concept drawn from Anderson's model), examined to establish whether these data were similar or different, and additional categories were developed based on this to capture similarities and differences between the data (Velestianos, 2013).

Since thematic content analysis requires researchers' immersion in data to identify particular themes, categories and patterns that allow the researchers to make meaning from the data, patterns identified in the data (e.g., interviews) were compiled and reanalysed across different data (i.e., categories and themes 
based on Anderson's model) until the data had been saturated and could be grouped into major themes (Velestianos, 2013). The result of this constant comparison method (Glaser \& Strauss, 1967) of interview data with categories from Anderson's model yielded five categories (see Table 1).

Table 1

Coding of lecturer and student interview excerpts

\begin{tabular}{lll}
\hline $\begin{array}{l}\text { Type of } \\
\text { Interaction }\end{array}$ & Categories & Example of lecturer and student interview excerpts \\
\hline $\begin{array}{l}\text { Student- } \\
\text { student }\end{array}$ & Affinity driven interactions & We formed Facebook tutorials groups for discussing \\
interactions & & some assignments and collaborative IT projects \\
(Student)
\end{tabular}

Our Facebook group on software development is cool because we share innovative ways of open source software development (Student).

The Facebook reading group is private as only students and tutors are welcome but not lecturers (Student)

\begin{tabular}{lll}
\hline $\begin{array}{l}\text { Student- } \\
\text { lecturer } \\
\text { interactions }\end{array}$ & Organisational functions & $\begin{array}{l}\text { Consulting with the lecturer on Facebook can tone } \\
\text { down the interaction in class because some students are } \\
\text { too garrulous. Facebook can moderate interaction and } \\
\text { give silent students a voice (Convenor) }\end{array}$
\end{tabular}

Facebook helps me in my lecture planning. When questions are posted online beforehand, it is easier for me to structure the lecture accordingly as opposed to spontaneous questions (Regular lecturer).

Facebook supports a "flipped classroom" where students discuss academic content out of classrooms and use classroom time to reflect on tasks (Guest lecturer).

\begin{tabular}{lll}
\hline $\begin{array}{l}\text { Student- } \\
\text { lecturer }\end{array}$ & Psychosocial affordances & Facebook can break boundaries in hierarchical learning \\
interactions & relations. It may also empower people to better express \\
themselves particularly those struggling to express \\
themselves in face-to-face contexts (Regular lecturer).
\end{tabular}

It creates a new culture of critical questioning, which breaks boundaries (Guest lecturer).

\begin{tabular}{|c|c|c|}
\hline & Facebook concerns & $\begin{array}{l}\text { I would never have opened a Facebook page had it not } \\
\text { been a requirement. I am planning to close it when I am } \\
\text { done with IS course (Student). } \\
\text { We were literally forced to join the IS Facebook group. } \\
\text { It was part of our course outline but I have not posted } \\
\text { anything (Student) }\end{array}$ \\
\hline & & $\begin{array}{l}\text { I do not like Facebook because it acts as a spying zone } \\
\text { for people in relationships. It is difficult to have a } \\
\text { private life when you are on it (Student) }\end{array}$ \\
\hline & & $\begin{array}{l}\text { It is scary to have your superior [lecturer] on Facebook } \\
\text { because they may snoop into your page (Student) }\end{array}$ \\
\hline \multirow{2}{*}{$\begin{array}{l}\text { Student- } \\
\text { content } \\
\text { interactions }\end{array}$} & Language development & $\begin{array}{l}\text { Sometimes, I sneak into friends' Facebook pages to } \\
\text { learn how they use language and expressions (Student). }\end{array}$ \\
\hline & & $\begin{array}{l}\text { The beauty of Facebook is that I can put my rough } \\
\text { ideas out there and my peers can correct English } \\
\text { [language] that I struggle [with] (Student) }\end{array}$ \\
\hline
\end{tabular}


Table 2

Coding of Facebook interactions

\begin{tabular}{lll}
\hline $\begin{array}{l}\text { Type of } \\
\text { Interaction }\end{array}$ & Facebook postings & Researchers' comments \\
\hline $\begin{array}{l}\text { Student-peer } \\
\text { interaction }\end{array}$ & $\begin{array}{l}\text { [Student Query (SQ)] Are there any reasons } \\
\text { why first year students do not want to major in } \\
\text { Information Systems?(Discussion Board Post }\end{array}$ & \\
$[\mathrm{DBP}])$ & & \\
& $\begin{array}{l}\text { [Student response (SR) 1] They all want to be } \\
\text { cliché and choose the CA [chartered } \\
\text { accounting] option haha (DBP) }\end{array}$ & $\begin{array}{l}\text { A satiric response founded on self- } \\
\text { projection-the view that students } \\
\text { doing Charted Accountants are less } \\
\text { trendy than their counterparts }\end{array}$
\end{tabular}

[SR 2] I think they know what they are in for that's why they're choosing the easy root! then again it's only as easy as the amount of work you put into it ... (DBP).

[SQ]-Hi... Just a little confused. Are we supposed to link our site to an actual database? As well as in the search function? (Wall Post [WP])

Student -peer consultation potentially creates knowledge producers and receivers among students

[Peer response] You can't get the Database connection fully functional to test. This is because we need to have the site published and Database on ASP enabled server ...

\begin{tabular}{|c|c|c|}
\hline \multirow[t]{2}{*}{$\begin{array}{l}\text { Student-content } \\
\text { interaction }\end{array}$} & $\begin{array}{l}\text { [Student] Hi. Our team has launched a website } \\
\text { that offers Essay writing service. If you need } \\
\text { College papers, Term papers, Admission } \\
\text { essay, Project essays, etc. We can help you } \\
\text { with any writing needed. Visit us now at: } \\
\text { http://www.customessayplus.com/ (Wall Post } \\
\text { [WP]) }\end{array}$ & $\begin{array}{l}\text { Academic empowerment through } \\
\text { resource sharing }\end{array}$ \\
\hline & $\begin{array}{l}\text { [Student] Someone just email me a link to a } \\
\text { summary of the [INF1011Y] textbook. Check } \\
\text { it out here: [weblink provided] (Inbox Post } \\
\text { [IP]). }\end{array}$ & $\begin{array}{l}\text { Students served as information } \\
\text { givers to peers }\end{array}$ \\
\hline \multirow[t]{2}{*}{$\begin{array}{l}\text { Lecturer-student } \\
\text { interaction }\end{array}$} & $\begin{array}{l}\text { [Student] I'm just confused as to what my } \\
\text { topic entails for the literature review. I'm } \\
\text { doing "what is a system? System thinking". ... } \\
\text { In the text book it is just about systems in } \\
\text { general ... (IP) }\end{array}$ & $\begin{array}{l}\text { Lecturer-directed inquiry } \\
\text { potentially reinforces academic } \\
\text { dependence and vertical authority. }\end{array}$ \\
\hline & $\begin{array}{l}\text { [Lecturer response] A system is an organised } \\
\text { collection of parts (or subsystems) that are } \\
\text { highly integrated to accomplish an overall } \\
\text { goal. The system has various inputs, which go } \\
\text { through certain processes to produce certain } \\
\text { outputs ... (IP) }\end{array}$ & \\
\hline
\end{tabular}

To improve on the dependability of results, the researchers reflexively analysed their own preconceptions of what was happening - what is often called bracketing (Giorgi, 1997). They continuously reflected on their analysis and interpretation, and persistently questioned the degree to which these analyses reflected their own individual preconceived understandings of the phenomena under investigation (Velestianos, 2013). More so, the researchers also compared and matched their different understandings to breach any conceived inconsistencies in the development of their categories. The researchers also shared their 
analytical framework with colleagues with experience in SNS research to improve on the credibility of results.

Facebook postings

The same constant comparison method adopted for interviews was also considered through comparing Facebook postings with categories used in Anderson's interaction model (see Table 2). To improve on the dependability of results, the researchers shared their analytical framework with colleagues with experience in SNS research. Inconsistencies identified in this analysis process were adjusted and addressed.

\section{Findings}

Of the 850 students in the three classes, only 165 joined the Facebook group. These learners posted 414 posts, comprising 154 wall posts, 121 discussion forum posts, and 139 private messages to the administrator in two semesters.

Of the 165 participants, $49 \%$ (81) of them were females, and 51\% (84) were males. As shown in the Table 3, more female students than males sent private messages to the administrator's inbox. The online administrator is the regular lecturer whose Facebook data the lead researcher collected. However, male students posted more public postings to the wall and discussion forums than females, suggesting that male students were more inclined than females to engage publicly.

Table 3

Postings to the online administrator's Facebook page by gender

\begin{tabular}{llll}
\hline Facebook & Gender & $\begin{array}{l}\text { Number of } \\
\text { Posts }\end{array}$ & Percentage \\
\hline \multirow{2}{*}{ Inbox posts } & Female posts & 75 & $54 \%$ \\
& Male posts & 64 & $46 \%$ \\
\cline { 2 - 4 } & Total & 139 & $100 \%$ \\
\hline \multirow{2}{*}{ Discussion forum } & Female posts & 51 & $42 \%$ \\
Posts & Male posts & 70 & $58 \%$ \\
\cline { 2 - 4 } & Total & 121 & $100 \%$ \\
\hline \multirow{2}{*}{ Wall posts } & Female posts & 65 & $42 \%$ \\
& Male posts & 89 & $58 \%$ \\
\cline { 2 - 4 } & Total & 154 & $100 \%$ \\
\hline
\end{tabular}

As Table 4 illustrates, task related queries dominated the three interactional spaces suggesting that Facebook offered a more convenient context for generating group responses to students during task execution than sending emails to individuals. Students posted their queries and accessed help whenever they encountered challenges with their assignments in computer labs. Course administration queries like confirmation of lecture venues and changes in time tables were also predominant as they expedited communication about logistics without having to wait for next lecture to give announcements.

Table 4

Nature of postings and their directions

\begin{tabular}{llll}
\hline $\begin{array}{l}\text { Type of query } \\
\text { /question }\end{array}$ & Inbox Postings & $\begin{array}{l}\text { Discussion } \\
\text { forum postings }\end{array}$ & $\begin{array}{l}\text { Wall } \\
\text { postings }\end{array}$ \\
\hline Assessment & 104 & 82 & 90 \\
Administration & 24 & 28 & 35 \\
Student feedback & 9 & 11 & 15 \\
Social & 2 & & 14 \\
\hline Total & 139 posts & 121 posts & 154 posts \\
\hline
\end{tabular}

Assessment comprised queries/questions on tasks, quizzes, tests, practical, exams, theory and marks. Administration queries involved general inquiries about administrative issues, extra classes and appointments. Student feedback comprised the expression of appreciation and complaints while social queries/questions related to students' general social activities. 
In total 35 students made 86 postings (the majority) that were directed at the online administrator. Their focus ranged from theory and technical problems, to practical issues for which they sought assistance. Although quizzes, tests and examinations are all task oriented activities, it is important to distinguish them by form, context and process. Quizzes were very short, multiple choice-based exercises assigned to be accomplished by students in laboratories. They were formative assessments and computer-mediated tasks that were often timed to allow for automatic log off when the regular time set lapsed. Tests were also formative assessments but involved paper based examinations conducted mid semester in lecture halls. Tests should be distinguished from examinations, which are summative processes meant to test student knowledge of learnt concepts at the end of the last semester. Tasks constituted individual and peer-based exercises that tested theoretical or abstract knowledge of issues or concepts while practicals were lab-based activities mediated by tutors that tested students' practical knowledge of Excel and Access.

Of the 15 topics discussed, 10 were initiated by the students, 3 by tutors and 2 by one of the researchers. These topics ranged from technical problem solving, literature review queries, student evaluation of weekly quizzes and the high brain drain among South African information technologists. Posts initiated by tutors related to information on student scholarships, part-time employment opportunities and students' experiences with project management. Lecturers only provided responses to student queries, basic course information and general administration information to colleagues via Facebook.

In total, 46 students sent 139 messages to the administrator's inbox. There were no posts directed at peers as these messages comprised private conversations between individual students. While the majority of students who participated on the Facebook group forum directed their queries to the online administrator, only six students initiated conversations that provided information to peers.

\section{Thematic analysis using Anderson's types of interaction}

This section discusses interview data from the course convener, online administrator and students who participated in the Facebook group. The interviews were conducted a few days after the course ended. The comments selected for discussion were chosen because these constituted some common threads across different Facebook spaces. These participants' experiences with Facebook are summarised using three of Anderson's interaction types: student-content, student-student and student-lecturer interactions, which emerged from interview and Facebook postings.

\section{Student-Content Interactions}

These revolved around individual student engagement with content, their individual contributions to different Facebook spaces and knowledge sharing.

\section{Gender asymmetry}

Gender asymmetry was the main power-related category under the theme student-content interactions. Student-content interactions exposed the unintended consequences of Facebook use such as differential participation of males and female students on Facebook. The dominance of male postings on public spaces (wall and discussion board) and female dominance of private spaces (Facebook inbox messaging) was self-evident from the number of their postings (see Table 3).

\section{Student-Student Interactions}

At student-student level of interaction, academic relations played out in three main ways - individual dominance, projection of the self and participation in collaborative projects. These issues are elaborated in subsequent sections.

Individual dominance in class

One of the reasons for educator adoption of Facebook was to prevent extroverts from dominating classroom interaction in ways that would contribute to the muting of previously disadvantaged students' (PDS) voices (see student-lecturer interaction in Table 1). Their silence was a consequence of peer dominance, personal difficulties in understanding academic content (academic challenge), the language of communication (see student-content interactions in Table 1) and socio-cultural challenges of fitting into 
the elite mould of university education. As literature suggests, irrespective of their level of achievement in high school, students are not sufficiently equipped with language proficiency and personal competencies (life skills) to successfully pursue studies in South African higher education (Central University of Technology, 2012). Public and private engagement channels on Facebook therefore, were envisaged to create opportunities for social learning of English language by previously disadvantaged students.

The low ICT literacy of PDS also explained their limited engagement on Facebook, which potentially reproduced disadvantage and accentuated academic hierarchies. Statements like "I only started using computers at university. My friend created my first e-mail account for me" (Student Interview 7) attest to this limited experience with ICT. While some students may not have joined Facebook because they "struggle[d] to see the academic worth of SNS in their learning" (Student interview 9) others might have conceived it to be dissociated with their social practices. These students might have benefitted from training in productive use of Facebook accounts. The course convener noted that:

\begin{abstract}
Some students particularly the previously disadvantaged, do not know how to use Facebook. Some haven't seen computers in their lives. Those who have been using it since high school are the ones posing the questions, so academics need to create mechanisms for levelling the playing field possibly by creating Facebook accounts for students immediately when they arrive (L2).
\end{abstract}

Essentially, these students' participation on Facebook was mixed. For some, it constituted a reproduction of disadvantage, while for others it played out as transformation of experience that allowed them to broaden their repertoire on digital skills. This transformation included sharing of IT knowledge (see the second conversation under student-peer interaction in Table 2) as well as academic essay writing services (see student-content interaction in Table 2).

\title{
Projections of the self
}

These manifested in student informal conversations about the status of the IS discipline. One student sought his peers' opinions on the reasons why fewer students chose to major in their discipline. Although important information emerged about the workloads involved in IS in progressive years, some students exploited the opportunity to caricature other disciplines and to elevate their discipline as superior (see student-peer interaction category in Table 2). Facebook also enhanced the management of self impressions through "postings of pictures of exclusive student halls of residence, trendy weekend activities like parties and elite sports like golf" (Student Interview 22). This served to project the superiority of the individual, their personality and their discipline over those of peers.

\section{Collaborative projects}

Academic relations were not exclusively about hierarchical dominance but rather collaboration as well. Some students collaborated on their IS projects via Facebook tutorial groups in ways that were academically empowering (see student-peer interactions in Table 1). Such groups demonstrate student creativity and ability to think innovatively about Facebook beyond the uses envisaged by educators.

\section{Student-Lecturer Interactions}

\section{Breaching hierarchical boundaries}

Facebook provided a quasi-formal space for student consultation with educators that breached the hierarchical boundaries between them. The affordances for private and even anonymous communication allowed students to overcome status-related hierarchies often immanent in face-to-face communication. In particular, shy, low esteem students employed private spaces to consult with lecturers and knowledgeable peers without the fear of prejudice, public ridicule or being put on the spot. For them Facebook private conversations were critical to knowledge construction:

On Facebook, I feel more comfortable asking questions to the lecturer because it feels more private. In class, my peers often grumble that I shouldnot waste their time so I am wary of asking in lectures (Student 2). 
The course convenor also concurred:

The unanticipated advantage of Facebook is that shy students are able to complain more when their personality is "hidden" than when known. Some students fear the lecturers so they cannot come to complain face-to-face or in big lectures. But on Facebook they boldly articulate their problems (L3).

Some students affirmed this lecturer's view when they claimed that they felt "terrified when required by the lecturer to speak up in lectures" but on Facebook they "felt at home to ask critical questions privately" (Student interview 32). More so, students claimed that on Facebook they "had more time to reflect and process [their] thoughts before responding to queries" than in lectures where "there [was] pressure to think on your feet when picked upon by the lecturer" (Student interview 43). By empowering students to articulate themselves in a less threatening space, Facebook enhanced student agency to participate in knowledge production processes, which contributed to the breaching of perceived academic hierarchies through open critical dialogue.

\section{Academic compulsion}

Since many previously advantaged students were already using Facebook for social networking when its academic use was recommended, they generally conceived it as a personal technology they discovered and brought with them into university. This contrasts with the LMS, which they regarded as an institutionally sanctioned platform, whose use was compulsory. However, since Facebook use was based on personal need, some students chose not to join the Facebook discussion forum. While the few students who perceived the academic value of Facebook group joined it voluntarily, others felt that they were forced to join. The latter often resisted this compulsion by not using it at all. This compulsive element was also reported by the regular lecturer (online administrator):

Most of the questions asked by students who normally consult with me face-to-face, I would have answered them on Facebook. So I "force" them to use Facebook unless it is a specific question that I have not answered (L1).

Academic compulsion demonstrates the lecturer's authoritative position and her capacity to direct student actions in ways that they might not otherwise follow. Yet other students played it safe by "read[ing] messages that other students posted than post comments" themselves (Student interview 47).

Vertical surveillance and privacy violations

The low academic appropriation of Facebook by many students was due to: perceptions of vertical and horizontal surveillance by academics and peers respectively and perceived violations of information privacy. Statements like "I do not like Facebook because it acts as a spying zone for people in relationships. It is difficult to have a private life when you are on it" (Student interview 13) and "it is scary to have your superior (lecturer) on Facebook" (Student Interview 9) demonstrate this anxiety. Other students however professed their relative ease with Facebook. For them, accessing peers' previous postings or comments did not constitute a breach of privacy for the value of collective knowledge sharing overrode individual privacy considerations.

\section{Discussion and implications}

This section mainly discusses the potential of Facebook to reinforce and disrupt academic relations in traditional learning contexts. Firstly, interactions mediated by Facebook triggered differential participation among students of different gender judging from the volume of their postings. This finding buttresses Vedantham's (2011) report on gender differences in video creation on Facebook, where men reported more participation in video creation and editing than females. If participation on Facebook spaces contributed directly to academic empowerment, then male students were potentially more empowered than their female counterparts. That said, there could be uncertainties about academic power on Facebook given that social presence and lurking also constitute expressions of participation, which were not factored in the number of Facebook postings.

More so, differential participation also featured in male students' general preferences for public Facebook spaces while female students preferred private spaces. Public postings tend to attract responses from 
wider audiences than private postings, with the implication of heightened meaningful engagement and academic authority. These different preferences in postings support Hoy and Milne's (2010) findings that women were significantly more concerned than men about the privacy of personal information posted on Facebook. In addition, women engaged in noticeably more proactive privacy protection behaviour particularly data usage by third parties compared with men (Hoy \& Milne, 2010). The aforementioned finding on public/private preferences is also consistent with Carstensen's (2009) contention that patriarchal mechanisms have been reproduced in public (online) spaces, where weblogs written by men attract more attention because they deal with public issues while female blogs are more inclined towards private issues. Inferring from Carstensen's (2009) observation, females' private postings could be attributed to their internalisation of private dialogue, possible fear of negative judgment and introversion when pressured to engage in the public domain. Baxter-Magolda's (1992) research on university students' gendered ways of learning suggests that for females, the reception of knowledge is conceived as a private enterprise involving the productive use of interpersonal relationships while males master knowledge through public deliberation in public spaces, challenging peers' views and adopting more critical stances. The male inclination towards public expression insinuates a desire for self-articulation in public domains.

The reproduction of asymmetrical participation online based on gender suggests that patriarchal influences may continue to shape academic relations online. The implications of these findings for pedagogy is that educational benefits can only be derived when new learning designs mediated by SNS are accompanied by a transformative teaching culture. The new learning design should take cognisance of students' varying abilities to engage publicly, embrace their different learning styles and accommodate the social networked practices they are familiar with.

Lecturer-student, student-peer and student-content interactions on Facebook also fostered psychological empowerment. For instance, from a horizontal academic relations perspective, academically motivated students who scaled up participation on Facebook potentially evened out the dominance of the few talkative students in lectures. This supports claims about social technologies' potential to address the constraints imposed by formal lectures (Hodgkinson-Williams \& Ng'ambi, 2009) like lecturers' requirements for students to make contributions while standing up, which potentially discourages the participation of shy, less confident students. From a hierarchical academic relations perspective, the psycho-social effects of Facebook-mediated interactions included the breaching of hierarchical barriers between academics and students and enabling cultural assimilation by students. The sustained communication and psychological influence embodied in question-based interaction, need-based support and collective sharing of disciplinary information breached the transactional distance between educators and students. Moore (1997) describes transactional distance as the psychological and communicative space to be crossed by educators and students who are separated by physical distance in their knowledge sharing processes. The aforementioned findings on breaching social barriers dovetail with Evans' (2010) claim that SNS enable humans to overcome social hierarchies by allowing ordinary people to engage with prominent personalities such as famous celebrities as well as people of diverse nationalities. Social network practices, such as friending and following, potentially increase students' access to their educators' personal histories in ways that might relax or weaken the academic authority of educators (Lytle, 2011).

Since psychological empowerment was fostered through both vertical (lecturer-student) and horizontal (student-peer and student-content) interactions, educators need to use Facebook to broaden their interactions with students on and off campus. For instance, in African environments where access to learning networks is limited beyond the institutions for off campus students or all students during vacations, SNS can serve as useful educational tools for educator provision of additional learning resources (e.g., readings to consider during vacations in preparation for the following semester). As such, student participation in educational activities might not be disrupted due to limited connectivity when social networking is seamlessly integrated into traditional instruction.

Above all, while the long-term goal of Facebook interaction was promoting academic networking among peers, there was little evidence for this, as the lecturer dominated interactions on Facebook. A combination of factors explains this lecturer dominance; limited academic maturity of students as university entrants, students' limited conceptualisation of academic application of a social technology, and the lecturers' dependable positions as academic authorities. This lack of academic maturity and limited scholarly presence of first years resonate with literature on undergraduates' ways of learning. 
Baxter-Magolda's (1992) study on first years' ways of learning concludes that most of them exhibit absolute knowing - they tend to conceive knowledge as certain (involving mere acquisition of knowledge) and expect assessments to emphasise the reproduction of knowledge. Therefore, although some students were digital natives who had grown up in technology-rich environments, they had not mastered the contextualised application of social technologies.

The dominance of the lecturer in Facebook, a space that was supposed to be student regulated, suggests that educators tended to use SNS to support didactic teaching. On the contrary, educators need to use Facebook productively to encourage academic networking, creativity and the building of online learning communities (Attwell, 2007). Designing learning tasks and activities that require group collaboration and peer-based problem solving via Facebook as well as expecting students to develop authentic learning resources mediated by Facebook would empower them to meaningfully engage via these spaces. Arnold and Paulus (2010) highlight that ideally, SNS should emphasise community and collaboration as they are designed to combine individual profile pages with group interaction tools, such as chats, blogs, and discussion forums. Perhaps, tutors (whom students might conceive as not that distant from them in terms of status) may need to take a more direct role in student engagement and moderation of Facebook discussions, while educators maintain some social presence to allay the fears of authority dominance and vertical surveillance. This would make students more at ease on Facebook. Perhaps, maintaining frozen relations (i.e., loosely tied, relaxed relations) with educators could enhance sustained vertical interactions without necessarily blurring professional boundaries. More so, the involvement of external, disinterested opinion leaders to guide students in the navigation and productive academic uses of Facebook would also be necessary.

Overall, the multiplicity of responses to the educators' expectation for student participation on Facebook (e.g., compliance, lurking, resistance and non-participation) demonstrate that power relations are not necessarily uni-directional and rigid. Rather they provide enablers and constraints for particular forms of conduct with multiple consequences. As Clegg (1989, p. 17) rightly observes, power is a "discursive field of force" socially constituted by everyday human interaction and human agency that is both liberating and constraining. That said, the implication of the aforementioned citation for learning is that the academic value of joining Facebook might increase over time as useful information (questions and answers) becomes available.

In addition to the intricate interplay of academic relations, student concerns about the academic appropriation of Facebook needs to be acknowledged. While literature tends to be positive on the possibilities of using SNS to break down hierarchies and encourage disadvantaged students to participate, our results indicate that this was not always the case. In fact, students felt to be under surveillance. These feelings were attributed to: Facebook's lack of information and control privacy, its blurring of academic and personal spheres and academic compulsion. This view buttresses Ivala and Gachago's (2012) finding that students often struggle to reconcile Facebook's blurring of social and academic life and some students resent the lecturers for forcing themselves into what they perceive as their private spaces. The "mediated public" (Boyd, 2007, p. 2) nature of Facebook interactions also compromised privacy and threatened to expose students' ever changing relationship statuses.

To address the aforementioned concerns about the academic use of Facebook, educators are encouraged to demonstrate the authentic value of integrating social technologies into the curricula in ways that transcend the perceived hype that comes with them. The transformation of Facebook use from interactions based on questions towards its adoption for the development of novel IT projects and applications by students might be a more advanced use of the site.

\section{Conclusion}

Interactions mediated by Facebook generated a complex, discursive practice for the interplay of the enactment of asymmetrical power relations at different levels and increased student academic participation. In student-peer interactions, mixed results persisted through female students' domination of Facebook private spaces and male students' hegemonic presence on public spaces. More so, in these horizontal academic relations, Facebook mediated both the mutually constitutive reproduction and contestation of academic power. Reproduction of asymmetrical power unfolded through the sustained dominance of some voices previously muted in lectures while the contestation of power manifested in the 
reinforcement of agency. These contradictory outcomes depended on the intensity and nature /focus of the uses of Facebook including the academic motivation of the students irrespective of their learning history. For instance, academically motivated PDSs used the platform to affirm their academic presence, generate and share academic resources and develop academically meaningful relations with knowledgeable peers.

In student-lecturer interactions, Facebook exhibited the enactment of hierarchical authority through students' heightened dependence on the educator for academic support. A question and answer-based model of using Facebook entrenched student expectation for educators to be on their backs. Paradoxically, for academically motivated students, increased interaction with the lecturer on Facebook contributed to the breaching of the transactional distance between the educator and themselves through the replacement of fleeting off-line relations with meaningful, online engagement in context.

Overall, Facebook participation was highly differentiated to the extent that segments of heightened academic engagements were sometimes interrupted by the projection of the self. This behaviour was not necessarily disruptive, but could be conceptualised as reproduction of social power mutually co-existing with subversion of relations and redemption of agency lost in lectures, which were dominated by a few voices. Perhaps, this positive energy and expression just needed to be redirected towards academic activities to increase its value.

However, Facebook appropriation was not without challenges. The adoption of Facebook for education accentuated student fears of academic surveillance by educators and concerns about potential violations of individual privacy in "mediated public" (Boyd, 2007, p. 2) spaces. Facebook also exposed the tensions and contradictions between its unpopular compulsory use in education, which generated limited participation and outright resistance and its strategic use for academic networking by a handful of students.

\section{References}

Anderson, T. (2004). Towards a theory of online learning. Edmonton: Athabasca University Press.

Arnold, N. \& Paulus, T. (2010). Using a social networking site for experiential learning: Appropriating, lurking, modelling and community building. Internet and Higher Education, 13, 188-196.

Attwell, G. (2007). Web 2.0 and the changing ways we are using computers for learning: what are the implications for pedagogy and curriculum. Pontydysgu: E-learning Europa Information directory. Retrieved December 5, 2007, from http://www.elearningeuropa.info/files/media/media13018.pdf

Baxter-Magolda, M. (1992). Knowing and reasoning in college: Gender-related patterns in students' intellectual development. San Francisco: Jossey-Bass.

Boyd, D. (2007). Social network sites: Public, private, or what? Knowledge Tree, 13, May. Retrieved June 13, 2007, from http://kt.flexiblelearning.net.au/tkt2007/?page_id=28.

Bozalek, V; \&Boughey, C. (2012). (Mis)framing higher education in South Africa, Social Policy and Administration, 46(6), 688-703

Carstensen, T. (2009). Gender trouble in Web 2.0: Gender relations in social network sites, Wikis and Weblogs. International Journal of Gender, Science and Technology, 1(1), 106-127.

Central University of TechnologyProspectus (2012). Retrieved May 13, 2013, from www.cut.ac.za/download/prospectus 2012

Clegg. S. (1989). Frameworks of power. London: Sage publications.

Cummins, J. (1997). Minority status and schooling in Canada. Anthropology and Education Quarterly, $28(3), 411-430$.

Dixon, E. (2012). Building a model for online distance courses through social media and networks. International Journal of Virtual and Personal Learning Environments, 3(3), 81-94.

Envision Media 360 (2013). Facebook vs Twitter vs Pinterest - 2013 statistics [Infographics].Retrieved December 15, 2013, fromhttp://www.envisionmedia360.com/infographics/facebook-vs-twitter-vspinterest-2013-statistics-infographic-719

Evans, S. (2010). Social media allows us to break boundaries. Social Marketing forum. Retrieved March 23, 2013, from http://www.socialmarketingforum.net/2010/11/sarah-evans-social-media-allows-us-tobreak-boundaries/

Fouchè, C \& Schurink, W. (2011). Qualitative research designs. In A. De Vos, H. Strydom, C. Fouchè, C. Delport, (Eds.), Research at grassroots: For the social sciences and human service professions (pp. 307-327). Pretoria: Van Schaik Publishers. 
Giorgi, A. (1997). The theory, practice, and evaluation of the phenomenological method as a qualitativeresearch procedure. Journal of Phenomenological Psychology,28(2), 235-260.

Glaser, B. G., \& Strauss, A. L. (1967). The discovery of grounded theory: Strategies for qualitative research. New York: Aldine De Gruyter.

Hodgkinson-Williams, C. \& Ng'ambi, D. (2009). Case study 5: Mobile learning: Report of the Opening Scholarship Project. Cape Town: Centre of Educational Technology, University of Cape Town.

Hoy, M. \& Milne, G. (2010). Gender differences in privacy-Related measures for young adult Facebook users. Journal of Interactive Advertising, 10 (2), 28-45.

Infographic Labs (2012). Facebook 2012 (Posted February 15, 2012). Retrieved May 17, 2013, fromhttp://infographiclabs.com/infographic/facebook-2012/

Ivala, E. \& Gachago, D. (2012). Social media for enhancing student engagement: The use of Facebook and blogs at a University of Technology. South African Journal of Higher Education, 26(1), 152-167.

Lytle, R. (2011). Student-teacher social media restrictions get mixed reactions some school districts have prohibited social media contact between students and teachers. Retrieved February 17, 2013, fromhttp://www.usnews.com/education/high-schools/articles/2011/08/10/student-teacher-socialmedia-restrictions-get-mixed-reactions

Maranto, G. \& Barton, M. (2010). Paradox and promise: MySpace, Facebook, and the sociopolitics of social networking in the writing classroom. Computers and Composition, 27, 36-47.

Moore, M. (1997). Theory of transactional distance. In D. Keegan (Ed), Theoretical Principles of Distance Education (pp. 22-38). New York: Routledge.

Rambe, P. (2011). Exploring the impacts of social networking sites on academic relations in the university. Journal of Information Technology Education, 10, 271-293.

Rambe, P. (2012). Social media-enhanced phones for productive learning of South African postgraduate students. International Journal of Mobile and Blended Learning, 4(2), 49-66.

Rambe, P. \& Ng'ambi, D. (2011). Towards an information sharing pedagogy: A case of using Facebook in a large first year class. Informing Science:The International Journal of an Emerging Transdiscipline, 14, 61-89.

Schurink, W., Fouchè, C. \& De Vos, A. (2011). Qualitative data analysis and interpretation. In A. de Vos, H. Strydom, C. Fouchè \& C. Deport. (Eds.), Research at Grassroots: For the social sciences and human services professions (pp. 397-423). Pretoria: Van Schaik Publishers.

Selwyn, N \& Grant, L. (2009). Researching the realities of social software use - an introduction. Learning, Media and Technology, 34(2), 79-86.

Vedantham, A. (2011). Making YouTube and Facebook videos: Gender differences in online video creation among first-year undergraduate students attending a highly selective research university (Doctoral dissertation). University of Pennsylvania Graduate School of Education.

Veletsianos, G. (2012). Higher education scholars' participation and practices on Twitter. Journal of Computer Assisted Learning, 28, 336-349.

Veletsianos, G., \& Kimmons, R. (2012). Scholars and faculty members' lived experiences in online social networks, Internet and Higher Education, 16, 43-50.

Veletsianos, G. (2013). Open practices and identity: Evidence from researchers andeducators' social media participation. British Journal of Educational Technology, 44(4), 639-651.

Corresponding author: Patient Rambe, pjoerambe@gmail.com

Australasian Journal of Educational Technology (C) 2014.

Please cite as: Rambe, P., \& Ng'ambi, D. (2014). Learning with and from Facebook: Uncovering power asymmetries in educational interactions. Australasian Journal of Educational Technology, 30(3), 312325. 